\title{
Perancangan Ulang Tata Letak Fasilitas Pabrik Di CV. Apindo Brother Sukses Menggunakan Metode Systematic Layout Planning (SLP)
}

\author{
Iksan Adiasa ${ }^{* 1}$, Ryan Suarantalla ${ }^{2}$, Muhammad Sayyid Rafi ${ }^{3}$, dan Koko Hermanto ${ }^{4}$ \\ 1,2,3,4 Teknik Industri, Fakultas Teknik, Universitas Teknologi Sumbawa, \\ Jalan Olat Maras, Batu Alang, Kecamatan Moyo Hulu, Kabupaten Sumbawa, 84371, Indonesia \\ Email: iksan.adiasa@uts.ac.id ${ }^{1}$, ryan.suarantalla@uts.ac.id ${ }^{2}$, rmorlando8380@gmail.com $^{3}$, \\ koko.hermanto@uts.ac.id ${ }^{4}$
}

\section{DOI: 10.20961/performa.19.2.43467}

\begin{abstract}
Abstrak
Di dalam dunia industri, masalah tata letak pabrik maupun tata letak fasilitas dan peralatan produksi merupakan salah satu yang berperan penting dalam peningkatan produktivitas perusahaan. Tata letak yang tidak tepat dapat menyebabkan waktu pemindahan bahan menjadi tidak efektif karena jarak antar stasiun yang jauh. CV. Apindo Brother Sukses adalah perusahaan yang berfokuskan pada bidang jasa yang melakukan berbagai perlakuan terhadap suatu produk atau barang. Perlakuan yang dilakukan salah satunya yaitu pelapisan menggunakan listrik atau electroplating. Kegiatan penelitian ini bertujuan untuk memperbaiki proses produksi pelapisan Nikel chrome dan Gold Plating dan membuat tata letak fasilitas baru proses produksi pelapisan Nikel chrome dan Gold yang lebih efektif pada CV. Apindo Brother Sukses. Pengolahan data dilakukan dengan menggunakan metode Systematic Layout Planning (SLP). Hasil studi lapangan yang diperoleh dari penelitian ini adalah pada proses pelapisan nikel chrome dan gold masih mengalami panjangnya proses produksi oleh karena itu peneliti membuat rancangan layout proses produksi baru dengan panjang yang lebih pendek dan efektif. Hasil pembuatan layout usulan didapatkan improvement pengurangan jarak tempuh produksi sebesar 62,5\% untuk nikel chrome dan 73,5\% untuk gold.
\end{abstract}

Kata kunci: Tata Letak Fasilitas, Systematic Layout Planning (SLP), Layout Proses Produksi

\begin{abstract}
In the industry, the problem of plant layout as well as the layout of production facilities and equipment is one of the important things in company productivity. The incorrect layout can cause material transfer time to be ineffective due to the long distance between stations. CV. Apindo Brother Sukses is a company that focuses on the service sector that performs various treatments for a product or goods. One of the treatments carried out is electroplating. This research activity aims to improve the nickel chrome plating and gold plating production process and create a new facility layout for the more effective nickel chrome and gold plating production process at CV. Apindo Brother Success. Data processing was performed using the Systematic Layout Planning (SLP) method. The results of the field study obtained from this research are that the plating process of nickel chrome and gold is still experiencing a long production process, therefore the researchers made a layout design for a new production process with a shorter and more effective length. The result of making the layout improvement of the production travel honor pattern is $62.5 \%$ for nickel chrome and $73.5 \%$ for gold.
\end{abstract}

Keywords: Facilities layout, Systematic Layout Planning (SLP), Production Process Layout

\section{Pendahuluan}

Di dalam dunia industri, masalah tata letak pabrik maupun tata letak fasilitas dan peralatan produksi merupakan salah satu industri yang berperan penting dalam peningkatan produktivitas perusahaan. Tata letak pabrik adalah suatu landasan utama dalam dunia industri. Plant layout atau facilities layout didefinisikan sebagai tata cara pengaturan fasilitas-fasilitas pabrik guna menunjang kelancaran proses produksi, jarak material handling dalam area produksi akan memengaruhi lintasan dan waktu proses dari produksi.

${ }^{*}$ Corresponding author 
Tata letak fasilitas dan penanganan bahan adalah salah satu industri yang dapat memengaruhi kinerja dalam suatu industri. Tata letak yang tidak tepat dapat menyebabkan waktu pemindahan bahan menjadi tidak efektif karena jarak antar stasiun yang jauh. Kegiatan dalam industi harus diatur dan didesain sehingga tercipta kegiatan yang saling mendukung sesuai aliran bahan dan keterkaitan kegiatan. Tata letak yang baik adalah tata letak yang mampu memanfaatkan ruang untuk proses secara efektif agar dapat meningkatkan kualitas ruang serta meminimalkan biaya penanganan bahan.

Hadiguna dkk. (2008) mendefinisikan tata letak sebagai kumpulan unsur-unsur fisik yang diatur mengikuti aturan atau logika tertentu. Sistem material handling yang kurang sistematis menjadi masalah yang cukup besar dan mengganggu kelancaran proses produksi sehingga memengaruhi industri secara keseluruhan. Menurut Wignjosoebroto (2009), tata letak yang baik adalah tata letak yang dapat menangani kegiatan material handling secara menyeluruh. Sedangkan Purnomo (2004) menyebutkan tata letak fasilitas yang dirancang dengan baik pada umumnya akan memberikan kontribusi yang positif dalam optimalisasi proses operasi perusahaan dan pada akhirnya akan menjaga kelangsungan hidup perusahaan serta keberhasilan perusahaan.

Menurut Wignjosoebroto (2009), tata letak pabrik meliputi perencanaan dan pengaturan letak mesin, peralatan, aliran bahan dan orang-orang yang bekerja pada masing-masing stasiun kerja. Jika disusun secara baik, maka operasi kerja menjadi lebih efektif dan efisien. Menurut Purnomo (2004), tujuan utama perancangan tata letak adalah optimasi pengaturan fasilitasfasilitas operasi sehingga nilai yang diciptakan oleh industri produksi akan maksimal.

CV. Apindo Brother Sukses adalah perusahaan yang berfokuskan pada bidang jasa yang melakukan berbagai perlakuan terhadap suatu produk atau barang. Perlakuan yang dilakukan salah satunya yaitu pelapisan menggunakan listrik atau electroplating. Hasil yang sempurna tentu diinginkan oleh setiap perusahaan yang ingin melakukan electroplating atau pelapisan di tempat jasa tersebut. Karena itulah hasil pelapisan yang di lakukan CV. Apindo Brother Sukses sebagai tolak ukur keberhasilan jasa pelapisan yang dilakukan, dimana semakin banyak orang yang ingin melakukan jasa pelapisan di perusahaan maka semakin baik jasa pelapisan yang diberikan dan sebaliknya, semakin sedikit orang yang melakukan jasa pelapisan maka semakin rendah kualitas jasa pelapisan tersebut.

Kualitas jasa pelapisan yang kurang baik dapat menimbulkan masalah bagi perusahaan. Masalah tersebut dapat berbentuk keterlambatan, daerah proses produksi yang masih belum teratur dan bahan yang ingin di lapisi sangat jauh dari tempat workshop. Proses produksi yang berantakan dan tidak beraturan pada CV. Apindo Brother Sukses adalah penyebab utama masalah yang membuat proses produksi pelapisan menjadi lama dan layout tata letak fasilitas yang terlalu panjang yang menyebabkan lamanya proses pelapisan tersebut

Berdasarkan pengamatan peneliti selama satu bulan menunjukkan bahwa tata letak pabrik yang di CV. Apindo Brother Sukses kurang efektif karena masih banyak masalah dalam keterlambatan dalam proses produksinya yang banyak melewati waktu yang telah ditetapkan. Menurut Putri dan Ismanto (2019), tata letak fasilitas yang kurang baik akan menyebabkan keterlambatan penyelesaian produk dan dapat menambah biaya produksi. Berdasarkan hal tersebut peneliti melakukan perbaikan dengan memperbaiki tata letak yang ada di perusahaan. Dengan perbaikan tersebut, diharapkan keterlambatan dalam proses produksi di PT CV.Apindo Brother Sukses dapat berkurang dan proses produksi menjadi lebih efektif dan efisien. 


\section{Metode Penelitian}

Metode penelitian yang dilakukan diawali dengan studi literatur. Studi literatur dilakukan untuk mempelajari tentang tata letak fasilitas dan mencari tahu apakah sesuai dengan keadaan perusahaan dan mencari referensi tata letak fasilitas agar mudah dalam menyelesaikan permasalahan yang ada.

Selanjutnya dilakukan studi lapangan untuk mengamati setiap lokasi yang terdapat dilapangan dan mengetahui permasalahan yang ada dan menghitung jarak setiap proses produksi menggunakan meteran untuk memudahkan pembentukan layout sementara dari perusaan. Kemudian menjadikan landasan untuk memberikan keputusan layout baru untuk perusahaan. Penelitian ini dilakukan di Workshop CV. Apindo Brother Sukses Tambun, Kabupaten Bekasi Jawa Barat. Jasa Pelapisan yang di lakukan di CV. Apindo Brother Sukses diantaranya Nikel Chrome dan Gold Plating untuk melapisi berbagai jenis benda yang bisa menghasilkan aliran listrik. Peneliti mengamati tata letak fasilitas pabrik yang masih belum teratur. Adapun waktu dan tempat yang diteliti ini dilakukan dalam kurung waktu 1 bulan, terhitung dari tanggal 9 September 2019 sampai dengan 9 Oktober 2019.

Tahap selanjutnya dilakukan pengambilan data dengan menghitung dan mengukur bangunan maupun luas yang ada dengan menanyakan kepada pengawas lapangan dan menghitungbkembali untuk memastikan apakah jarak dan luas sudah sesuai menggunakan meteran yang ada, adapun data yang digunakan terdiri dari Data Primer dan Data Sekunder. Data primer didapatkan dengan melakukan wawancara dengan karyawan mengenai keterlambatan waktu produksi. Data sekunder yaitu melihat penelitian maupun studi kasus lain yang berhubungan dengan kasus masalah yang diteliti.

Setelah dilakukan pengambila data, selanjutnya pengolahan data dilakukan dengan menggunakan metode Systematic Layout Planning (SLP), dengan memodelkan lokasi dan dibuat layout lama dan layout baru untuk usulan perusahaan, kemudian untuk mencari penyelesaian masalah dimulai dari analisis masalah, pemetaan layout awal, pendekatan dengan Systematic Layout Planning (SLP), analisis Activity Relationship Chart (ARC), layout usulan dan tata letak fasilitas baru (Kartika, 2014; Tompkins dkk., 1996).

Data yang telah diolah kemudian dianalisis untuk mengetahui apakah hasil usulan layout yang didapatkan dapat mengurangi beban proses produksi dan waktu yang ada jika sesuai dan lebih baik maka hasil dinyatakan sukses, data penelitian yang diolah kemudian di analisis dan dijadikan pedoman untuk mengurangi masalah yang sedang terjadi dan sebagai solusi agar lebih efektif dalam tata letak fasilitas dan proses produksi pelapisan nikel chrome dan gold di CV. Apindo Brother Sukses.

\section{Hasil dan Pembahasan}

Hasil pengamatan yang diperoleh adalah aliran proses dalam pelapisan Nikel chrome dan Gold sangat panjang dan tidak efisien, maka dilakukan perancangan ulang tata letak fasilitas yang dimulai dari analisis aliran proses, selanjutnya dilakukan perhitungan jarak proses hadling layout awal. Total kebutuhan area proses pelapisan yang telah di rancang sebelumnya dengan penyesuaian kondisi pabrik. 


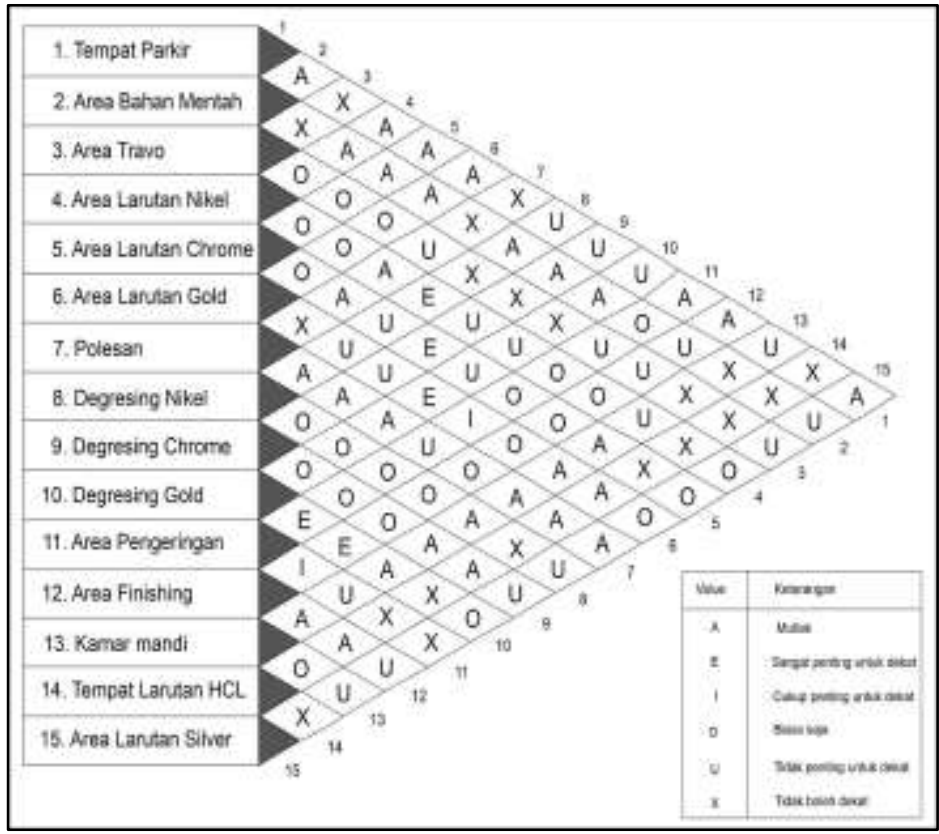

Gambar 1. ACR (Activity Relationship Chart)

Sebelum melakukan pembuatan layout baru kita harus mengetahui apa saja yang bisa di pindahkan atau di dekatkan dengan mengetahui Activity Relationship Chart (ARC) dengan ini hubungan antar tempat dan benda bisa diketahui, dan proses produksi dari nikel chrome dan gold bisa saling singkron dan efektif. Activity Relationship Chart (ARC) yang merupakan dasar dalam pembuatan alternatif tata letak dengan memperhatikan modifikasi dan batasan praktis. Untuk membuat rancangan tata letak dapat dibuat denah awal dan rute awal dengan sekala yang lebih kecil kemudian dibuatkan layout baru dalam tata letak dan proses produksi baru. Dengan begitu lebih mempermudah dalam menentukan perpindahan dan pembuatan layout baru untuk perusahaan.

a. Produksi nikel chrome Lama dan Baru

Berikut adalah layout produksi dari nikel chrome yang digambar kan pada gambar dibawah ini:

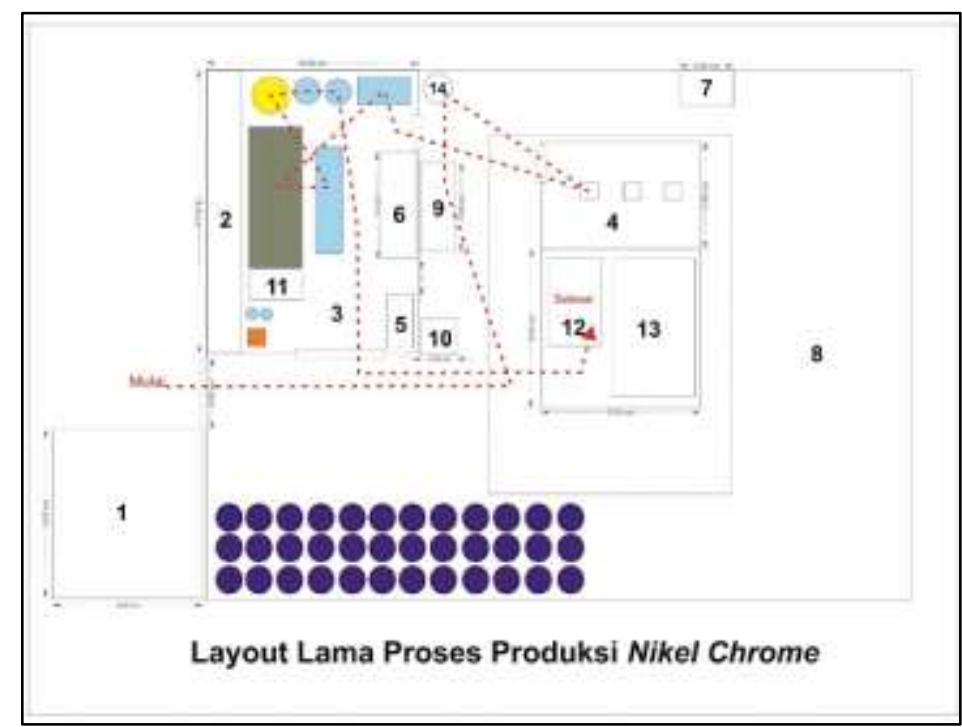

Gambar 2. Peta Proses Produksi Lama Nikel chrome 


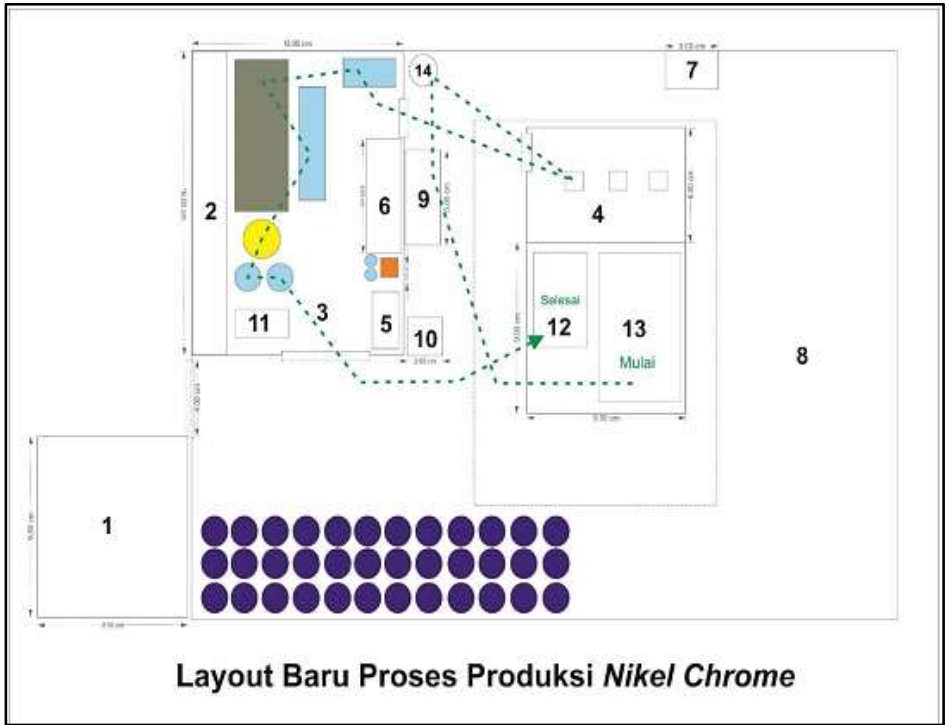

Gambar 3. Peta Proses Produksi Baru Nikel Chrome

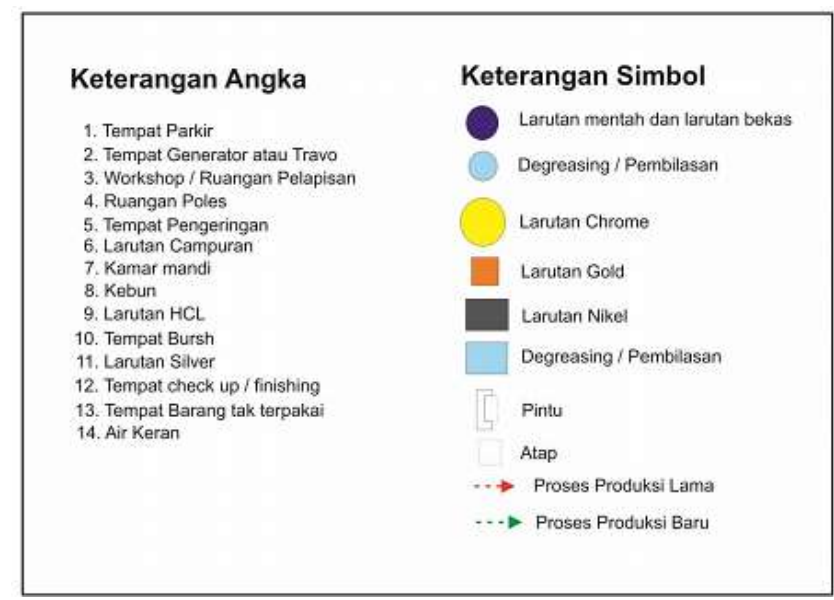

Gambar 4. Keterangan Denah Gambar

Proses produksi nikel chrome memiliki panjang produksi 178,5 m dengan penjabaran yang ditunjukkan pada gambar dibawah ini:

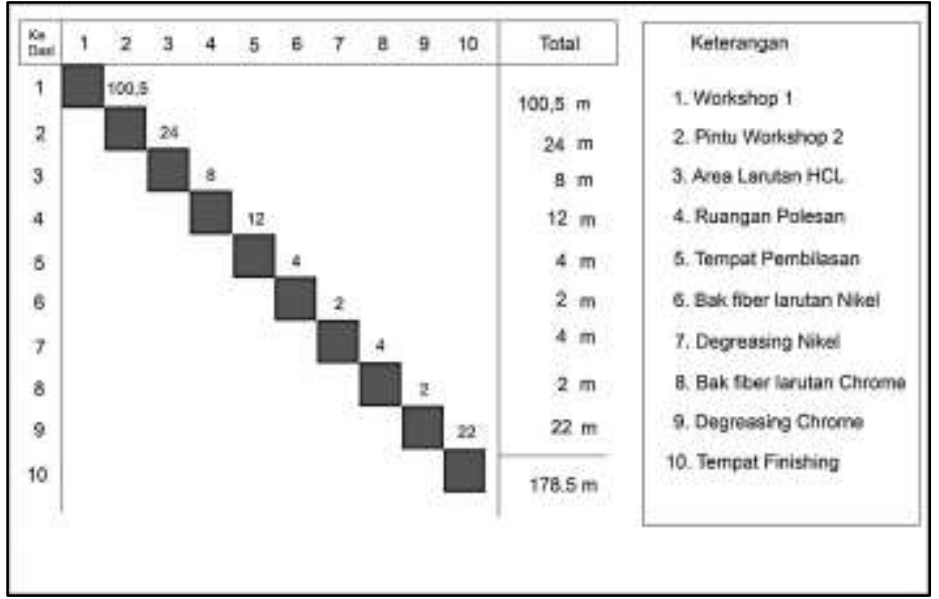

Gambar 5. Panjang Proses Produksi Lama Pelapisan Nikel Chrome 
Dari gambar 5 diketahui bahwa proses produksi nikel chrome samgatlah panjang yaitu 178,5 meter dikarenakan bahan mentah yang akan diproses di ambil terlebih dahulu di workshop satu yang menyebabkan proses produksi menjadi lama dan jauh serta beberapa tempat produksi yang menyilang atau tidak teratur, dan beberapa perubahan proses produksi yang baru yang dibuat untuk memudahkan dan memperpendek proses produksi nikel chrome di bawah ini.

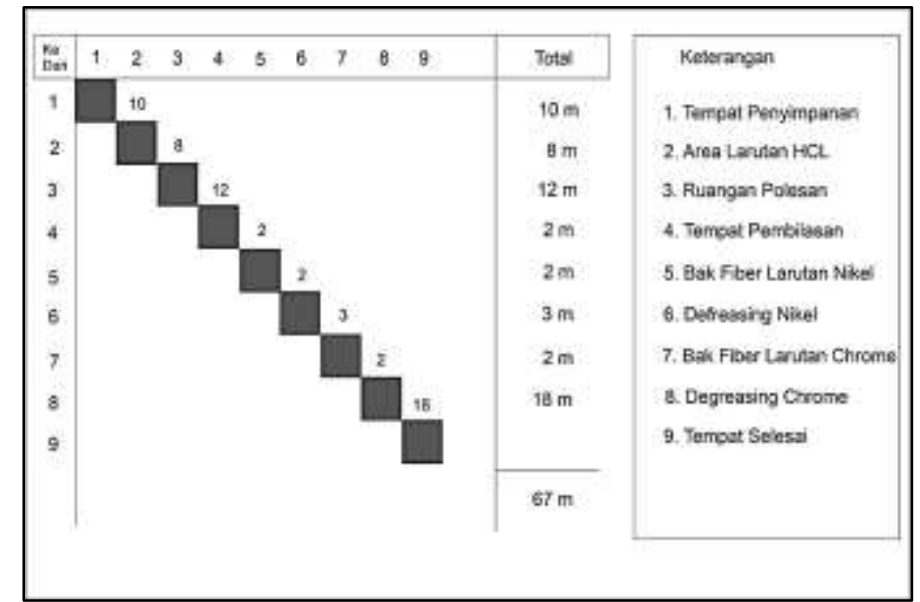

Gambar 6. Panjang Proses Produksi Baru Pelapisan Nikel Chrome

Dari gambar 6, produksi lama dan baru terlihat jelas perbedaan jaraknya yaitu dari 178,5 meter menjadi 67 meter dengan berkurangnya 111,5 meter proses produksi nikel chrome lebih cepat dan efektif serta mudah dalam mengejar ketepatan waktu, dengan jarak yang lebih pendek dan teratur membuat proses produksi nikel chrome lebih baik dengan tidak melakukan waste waktu karena jarak yang lebih panjang. Selain itu juga dapat melakukan penghematan biaya dari material handling karena jarak tersebut.

b. Produksi Gold Platting Lama dan Baru

Berikut adalah layout produksi dari gold platting yang digambar kan pada gambar dibawah ini:

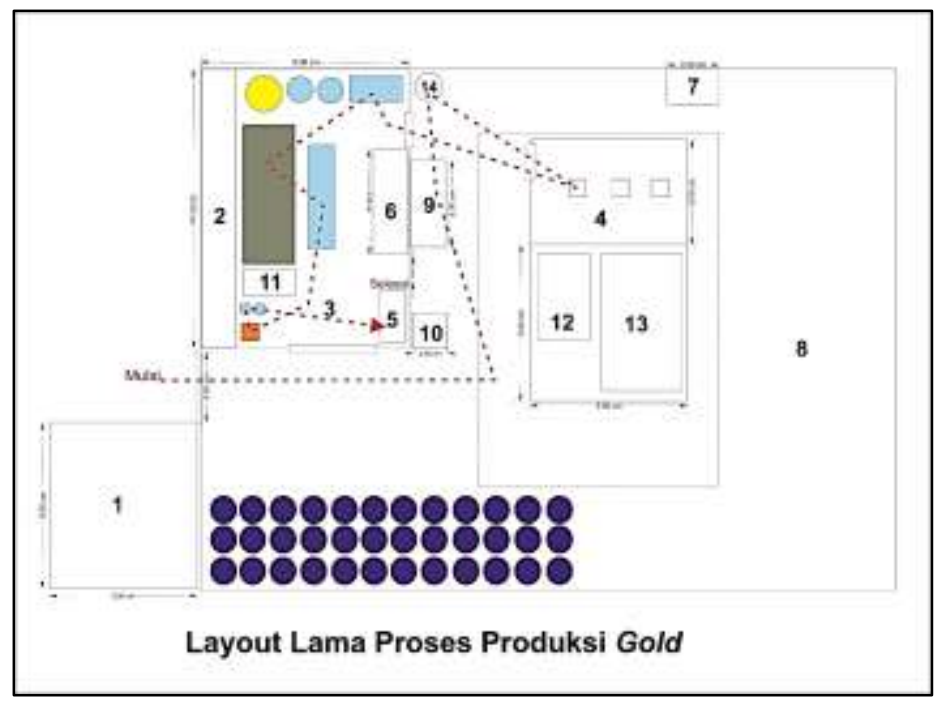

Gambar 7. Peta Proses Produksi Lama Gold Platting 


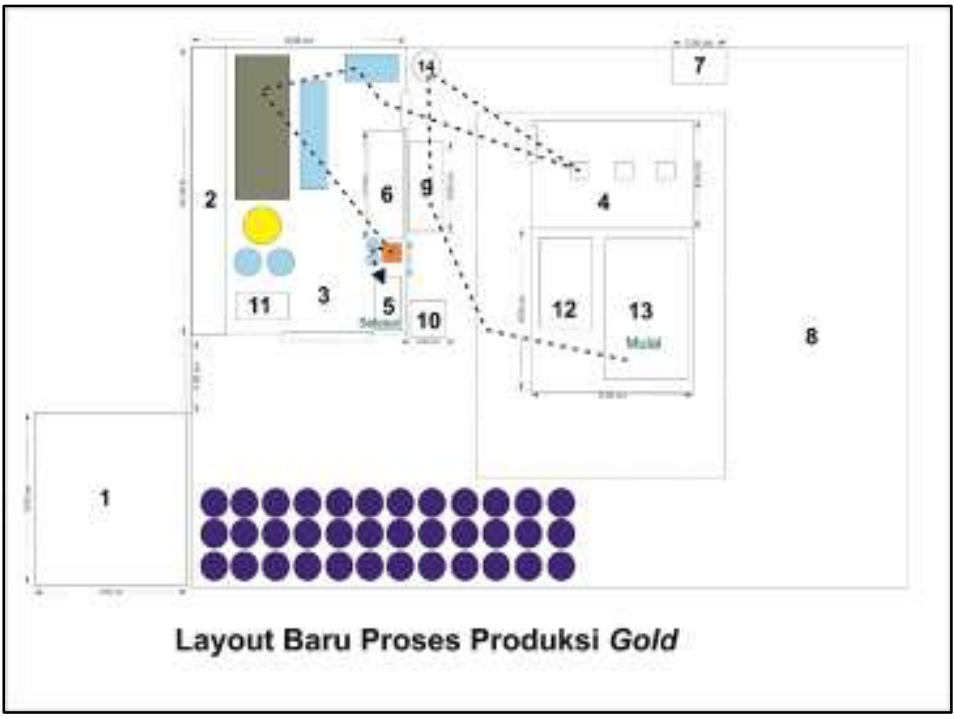

Gambar 8. Peta Proses Produksi Baru Gold Platting

Proses produksi lama Gold memiliki panjang produksi 162.5 meter dangan penjabaran sebagai berikut :

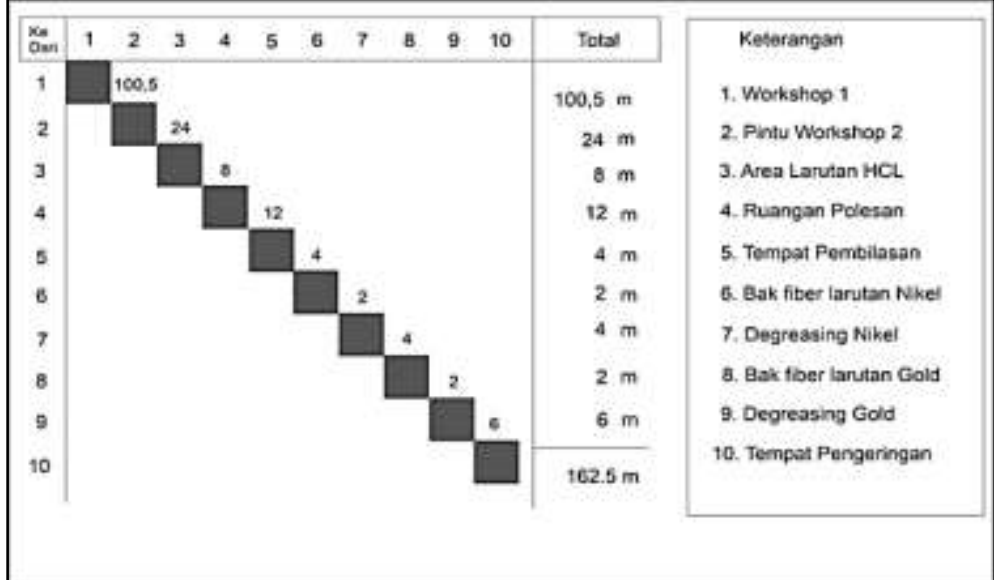

Gambar 9. Panjang Proses Produksi Lama Pelapisan Gold

Dari gambar 9 diketahui bahwa proses produksi Gold sangatlah panjang dikarenakan bahan mentah yang akan diproses di ambil terlebih dahulu di workshop satu yang menyebabkan proses produksi menjadi lama dan jauh serta beberapa tempat produksi yang menyilang atau tidak teratur, dan beberapa perubahan proses produksi baru yang dibuat untuk memudahkan dan memperpendek proses produksi gold paltting di bawah ini. 


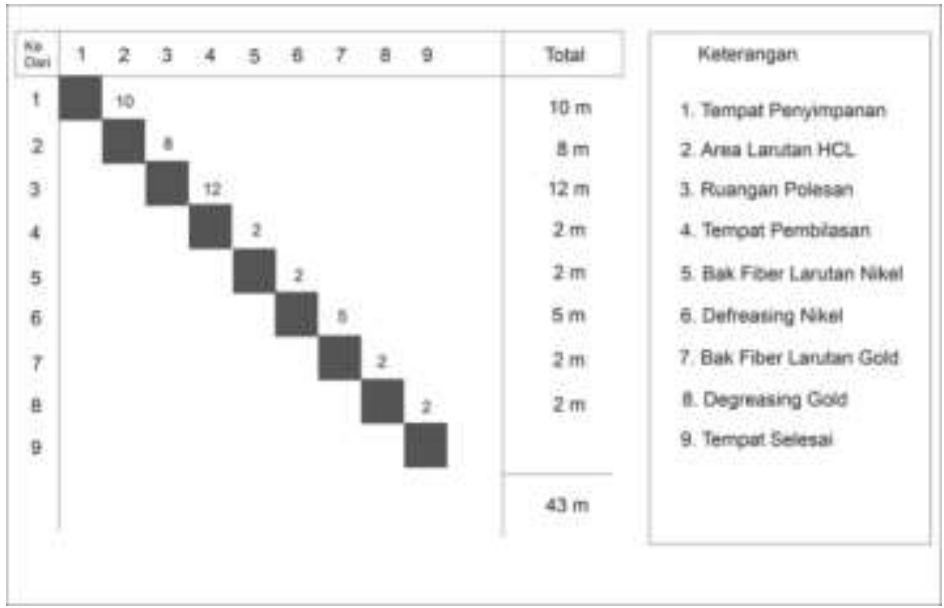

Gambar 10. Panjang Proses Produksi Baru Pelapisan Gold

Dari tabel produksi lama dan baru terlihat jelas perbedaan jaraknya yaitu dari 162,5 meter menjadi 43 meter dengan berkurang nya 119,5 meter proses produksi Gold lebih cepat dan efektif serta mudah dalam mengejar ketepatan waktu, dengan jarak yang lebih pendek dan teratur membuat proses produksi Gold lebih baik dan tidak membuang buang waktu karena jarak yang lebih panjang.

\section{Simpulan}

Berdasarkan data yang telah didapatkan dan diolah, dapat ditarik kesimpulan bahwa pada proses pelapisan nikel chrome dan gold masih mengalami panjangnya proses produksi, sehingga peneliti membuat rancangan layout proses produksi baru dengan panjang aliran proses nikel chrome $67 \mathrm{~m}$ dan gold $43 \mathrm{~m}$ dengan angka yang jauh lebih pendek dari sebelumnya dengan memanfaatkan tempat barang bekas yang tidak terpakai menjadi tempat penyimpanan untuk barang yang ingin dilakukan proses pelapisan, perancangan tata letak fasilitas baru membuat aliran proses pelapisan menjadi lebih pendek dan efektif dibandingkan aliran proses awal, dari 178,5 meter menjadi 67 meter dengan berkurangnya 111,5 meter atau terjadi improvement sebesar 62,5\% untuk aliran proses nikel chrome dan 162,5 meter menjadi 43 meter dengan berkurangnya 119.5 meter atau terjadi improvement sebesar $73,5 \%$ untuk aliran gold. Penelitian ini memiliki kekurangan dikarenakan pada penelitian ini tidak melakukan analisis terkait biaya material handling dan biaya produksi yang dapat berkurang. Sehingga penelitian lanjutan dapat dilakukan analisis terkait biaya-biaya tersebut.

\section{Daftar Pustaka}

Hadiguna, R. A., Setiawan, H., \& Oktaviana, H.S. (2008). Tata Letak Pabrik.Yogyakarta: Andi Offset.

Kartika, I. M. (2014). Perancangan Tata Letak Area Produksi dengan Menggunakan Metode ARC pada CV Gading Putih Di Semarang. CALYPTRA, 3(1), 1-18.

Purnomo, H. (2004). Perencanaan dan Perancangan Fasilitas. Yogyakarta: Graha Ilmu.

Putri, R. E., \& Ismanto, W. (2019). Pengaruh Perancangan Ulang Tata Letak Fasilitas di Area Operasional Kerja Berbasis 5S untuk Pengajuan Modal Usaha. Jurnal Dimensi, 8(1), 7189.

Tompkins, J. A., White, J. A., Bozer, Y. A., Tanchoco, J. M. A., \& Trevino, J. (1996). Facilities Planning. John Willey and Sons. Inc. 2nd edition. USA, 36-47.

Wignjosoebroto, S. (2009). Tata letak pabrik dan pemindahan bahan. Surabaya: Guna Widya. 